\title{
EL LADO OSCURO DE LA CIENCIA \\ (Hempel y Celine sobre Semmelweiss)
}

\section{EDISON OTERo}

1. En un pasaje particularmente poco feliz de "La Historia de la Ciencia y sus Reconstrucciones Racionales", Imre Lakatos desarrolla sus ideas sobre la historia interna (o lógica) e historia externa de la ciencia, y afirma: "Una forma de indicar las discrepancias entre la historia y su reconstrucción racional es relatar la historia interma en el texto e indicar en las notas los "desajustes" de la historia real con relación a su reconstrucción racional"l.

Como se sabe, las discusiones sobre lógica e historia de la ciencia están en el núcleo mismo del debate epistemológico actual. Tal vez, lo más fructífero del debate radica, precisamente, en haber puesto en el tapete de la discusión la importancia de las variables históricas y sociológicas en el desarrollo de los conceptos de la ciencia. Claro está, el debate consiste, por ello, en determinar el grado de esa importancia. Lakatos sostiene que la historia ex terna es definitivamente secundaria. Thomas Kuhn y Paul K. Feyerabend han defendido una postura antagónica. Se trata de un debate que atañe particular y decisivamente a las ciencias sociales y su futuro.

En las líneas que siguen se cxamina un caso específico y se contraponen dos modos de mirarlo y comprenderlo.

2. Carl Hempel, filósofo positivista, alude a Ignaz Semmelweiss (1818-1865) como un ejemplo de su concepción de la investigación científica. Aunque la trayectoria de Semmelweiss le parece "una página fascinante de la historia de la medicina"2, lo que recoge de ella -en directa relación al procedimiento del hombre de ciencia en su esfuerzo por explicar los fenómenos-así como lo que no es enfatizado y dejado en un segundo o tercer plano, advierten suficientemente sobre la manera como Hempel se representa la lógica de la ciencia. Nuestro propósito en estas límeas es poner la atención precisamente en aquello en lo que no enfatiza.

Lo cual se explica por una concepción de la ciencia que queremos examinar críticamente. Nos servimos para ello de una perspectiva diferente, en verdad contrapuesta, sobre el caso Semmelweiss, la que es adoptada por el novelista francés Louis-Ferdinand Celine. De su mano, furiosa y llena de lucidez acerca de la conducta humana en el mundo intelectual y científico, nos conducimos para el intento de demostrar que la lógica de la ciencia del positivismo es una lógica vacía, inerte y meramente formal, una perfecta escolástica de la ciencia y del modo como, en los hechos, parecen desarrollarse las explicaciones y se establecen las verdades de la ciencia.

3. Como una primera presentación de la franca oposición de perspectiva en la que están Hempel y Celine, valgan los párrafos que se citan a continuación; dice Hempel: "Como simple ilustración de algunos aspectos importantes de la investigación científica, parémonos a considerar los trabajos de Semmelweiss en relación a la fiebre puerperal"3. En cuanto a Celine, el asunto se presenta así: "Esta es la terrible historia de Felipe Ignacio Semmelweiss. Puede parecer un poco írida y a primera vista repeler, a causa de los detalles y de las cifras, de las minuciosas ¿xplicaciones. Pero el lector intrépido será rápidamente recompensado. Vale la pena y el esfuerzo. Habría podido renovarla desde su comienzo, maquillarla, hacerla más ágil. Era fácil y no he

${ }^{1}$ Este texto de Lakatos data de 1971 y está incluido en La Metodología de los Programas de Investigación Científica, : 978 , libro que recoge diversos trabajos del fallecido epistemólogo de origen húngaro.

${ }^{2}$ Filosofía de la Ciencia Natural, 1966. Versión española de Alianza Universidad, 1973, pág. 17, nota 1.

${ }^{3}$ Op. cit., pág. 16. 


\section{REVISTA DE SOCIOLOGÍA}

querido. La doy, por tanto, en lo que vale. La forma carece de importancia, lo que cuenta es el fondo. Y éste, supongo, es todo lo rico que se quiera. Demuestra el peligro que existe en pretender demasiada felicidad para los hombres. Es una vieja lección, siempre actual... Suponed que, de la misma manera, surge hoy día otro inocente que se dedica a curar el cáncer. ¡ $\mathrm{Ni}$ siquiera puede imaginarse a qué son tendría que bailar de inmediato! ¡Resul taría verdaderamente fenomenal! Más le valdrá ser precavido. ¡Que mantenga perramente sus precauciones! ¡Más botín ganaría alistándose al instante en cualquier legión extranjera! Nada se da gratis en este bajo mundo. Todo se expía; el bien, como el mal, tarde o temprano se paga. El bien, forzosamente, resulta mucho más caro"4.

No puede dejar de tenerse en cuenta que contraponemos a un novelista y a un filósofo de la ciencia; más, lo que el primero muestra, mucho demuestra sobre lo que el segundo subestima. Hay diversidad de lenguajes, es cierto; pero la libertad expresiva del uno denuncia la escisión fundamental sobre la que se funda el otro, su extrema falta de encarnación. Para Celine, Semmelweiss expresa el drama trágico de la verđad, la manera chocante y agresiva que adopta la verdad para imponerse; esta manera no es su otra cara, el sello de la que Hempel describe: neutra, fría, imparcial, desinteresada, exenta de pasión humana, no desgarrada en el tráfico de la vanidad, la ambición y el gesto ruin, el dogma, la rigidez intelectual y la ortodoxia fanática.

Para Celine, la historia de Semmelweiss es el rostro de la verdad científica, de donde resultaría que la lógica de la ciencia, desencarnada, scría una máscara suya. Propiamente, una mascarada. En términos más bien filosóficos que dramáticos, se trataría de una flagrante abstracción.

4. Para Carl Hempel, los trabajos de Semmelweiss constituirían una ilustración representativa de la manera como proceden los hombres de ciencia. Nosotros suscribiríamos de inmediato tal afirmación si pudiese comprobarse que lo que Hempel quiere decir con "la manera como proceden los hombres de ciencia" es rigurosamente lo que, sostenemos, debe tenerse en cuenta. Inspirados en Celine, tenemos que concluir que Hempel procede a aislar un aspecto de la cuestión y lo llama "lógica de la ciencia". En consecuencia, abstrae y rompe algo que es una unidad real; en ese abstraer se pierden rasgos cardinales de la fisonomía de la verdad.

El proceso de investigación científica, sostiene Hempel, consistiría, en general, en el método de la contrastación de hipótesis. En la concepción de Hempel, la ciencia, o, más rigurosamente, el proceso de la investigación científica, no se asemeja en nada al modelo que de ella se hacen las concepciones tradicionales; en ésias, las cosas ocurrirían, ciñiéndose a la representación ingenua de la inducción; los datos, los hechos, por su mera presentación, sugerirían las leyes que describen sus relaciones. Habría un camino directo que va de la experiencia a las proposiciones de la ciencia y en ese orden, en esa sucesión temporal.

En primera aproximación, Hempel aparece oponiéndose a algo así como un proceso lineal con un punto de partida en que prevalecen valores del tipo de la objetividad, la neutralidad, el desinterés. En el comienzo de este camino, en consecuencia, la actitud del hombre de ciencia no se muestra influida por preconcepción alguna; no hay ideas, creencias, suposiciones, influencias, nada exterior o previo a la observación. Ėl ánimo es, pues, una "tábula rasa". El propio Hempel cita de un libro clásico y resume esta idea de la investigación científica, de acuerdo a la cual se distinguen en ella cuatro estadios.

1. Observación y registro de todos los hechos.

2. Análisis y clasificación de éstos.

\footnotetext{
${ }^{4}$ Semmelweiss, 1952. Versión de Alianza Editorial, 1968, págs. 21 y 22.
} 
3. Derivación inductiva de generalizaciones a partir de ellos.

4. Contrastación ulterior de las generalizaciones.

El desarrollo de las consideraciones de Hempel al respecto puede resumirse como sigue:

a) La investigación científica, de ese modo, es impracticable. "Ni siquiera podemos dar el primer paso, porque para poder reunir todos los hechos tendríamos que esperar, por decirlo así, hasta el fin del mundo; y tampoco podemos reunir todos los hechos dados hasta ahora, puesto que éstos son infinitos tanto en número cómo en variedad"5.

b) Cabría pensar que no se trata de todos los hechos, sino de todos los hechos relevantes. Sin embargo, hay que establecer respecto a qué serían relevantes. Pero, ¿cómo establecer lo relevante al problema que se investiga si, precisamente, se trata de algo que se busca explicar pues no se tiene respuesta establecida? Lo relevante no estú determinado, entonces, por el problema que se investiga sino "por el intento de respuesta que el investigador trata de darle en forma de conjeturas o hipólesis"?.

c) El análisis y clasificación de los fenómenos no puede realizarse sino sobre la base de una hipótesis acerca de como se relacionan tales fenómenos. "Sin esas hipótesis, el análisis y la clasificación son ciegos"7.

d) Hay que descartar la idea de que las hipótesis sólo aparecerían en el tercer estadio. "En resumen: la máxima según la cual la obtención de datos debería realizarse sin la existencia de hipótesis antecedentes, que sirvieran para orientarnos acerca de las conexiones entre los hechos que se están estudiando, es una máxima que se autorrefuta, y a la que la investigación científica no se atiene. Al contrario: las hipótesis, en cuanto intento de respuesta, son necesarias para servir de guía a la investigación científica"s.

Se supone, según Hempel, que Semmelweiss daría respaldo a su concepción de la investigación científica. Nos es necesario, en consecuencia, retrotraernos al siglo pasado y a las circunstancias en que aparece Semmelweiss. Su proceder sería el de un hombre de ciencia que levanta sus hipótesis sobre los fenómenos y procede luego a contrastarlas en la experiencia; su proceder probaría que no hay observación cxenta de ideas sino, más bien, una observación en la que se busca apoyo para las hipótesis que se han elaborado; no hay un hombre de ciencia neutral. Pero lo que Hempel parece dispuesto a aceptar al respecto no es exactamente lo que Celine va a ayudarnos a argumentar.

5. El asunto, decíamos, se retrotrae al siglo pasado y más específicamente a la década del 40; las cosas ocurren en el Hospital General de Viena, en las divisiones Primera y Segunda de Maternidad, donde un número alarmante de mujeres que han dado a luz contraen la fiebre puerperal y fallecen. Semmelweiss aparece como miembro del equipo médico de la Primera División, en la que mueren hasta un $11,4 \%$ de las internas, mientras que en la otra, extrañamente, la estadística desciende hasta un $2,7 \%$. El comienzo de la divergencia prende en Semmelweiss ante la contemplación de la actitud fatalista de la ciencia oficial; le repugnan la fraseología, cl ademán verbal, el manierismo doctoral, la parodia del "alto nivel". Le descomponen las siniestras y leliciosas intrigas académicas, y no puede alejar la impresión reiterada de la falsía ambiental. De súbito, sabrá que el enemigo clave no es la enfermedad, sino la estudiada ceguera de los doctos. Y este enemigo, fácilmente encolerizable, no dejará de advertir al hereje. Para Semmelweiss, el

\footnotetext{
${ }^{5}$ Op. cit., pág. 28.

${ }^{6}$ Op. cit., pág. 29.

${ }^{7}$ Op. cit., pág. 31.

${ }^{8}$ Op. cit., págs. 29 y 30 .
} 
saber oficial es un saber criminal: las infecciones se deben al pus y lo hay de diversas especies: muy trabado, de buena especie, laudable, etc; las infecciones se deben a la leche; las infecciones las trasmiten los estudiantes extranjeros, se deben a cambios atmosféricos... Toda esta jerga clasificatoria es doctrina inútil.

Louis-Ferdinand Celine lo describe así: "esta lúgubre fatalidad... aplasta a los hombres, a las mujeres y a las cosas que se agilan dentro de este círculo. Sólo él se opone (Semmelweiss) al destino y no es aplastado, pero sufre en todo momento, más que cualquier otro en Viena, en París, en Londres o en Milán. Todos ellos tarde o temprano, han doblado el cuello ante el paso de la plaga de la fiebre puerperal. Hipócritamente, en la indiferente sombra, han pactado con la Muerte. Y si los más sabios despiertan todavía de vez en cuando con sutiles conceptos, es porque han agotado los enanos recursos de sus cerebros enanos $y$, como no llegan nunca a nada, pronto vuelven a la grey oficial... La fiebre de las parturientas: ¡Terrible divinidad! ¡Detestable; pero tan corriente! Por fuerza, había de pertenecer al orden de las catástrofes cósmicas, inevitables... Los píos y despreciables la consideraban, sin confesárselo demasiado, como una especie de doloroso tributo, que frecuentemente tenían que pagar las mujeres del pueblo a su entrada a la maternidad. Algunas veces otros, desligados de la costumbre oficial, se indignan, enloquecen, arman el barullo... Entonces se nombraban Comisiones. Siempre reunieron a sabios responsables. ¿Qué fácil juego es presentar éstas sucesivas e interminables Comisiones de una manera ridícula!"9.

6. Todo este background, que recién comenzamos a bosquejar, no parece importar para Hempel. Ve a Semmelweiss como un adalid del método científico, que actúa cualquiera sea el contexto. En verdad, Hempel ve en Semmelweiss a la ciencia incontenible, pero no quiere verla en la institucionalidad científica que hará todo de su parte para aplastar al intruso.

En verdad, llegará hasta el crimen. Hempel no ve a la ciencia enfrentada a sí misma. Todo es claro, cristalino, transparente. Semmelweiss procederá a actuar de acuerdo al método de las hipótesis e irá descartándolas conforme la experiencia verificante lo imponga. A la opinión de que la fiebre provendría de cambios atmosféricos, responde que ella es incompatible con el hecho de que mientras la fiebre campea en el Hospital, casi no se registran casos en el resto de la ciudad y sus alrededores. La opinión de que el responsable sería el hacinamiento tampoco resiste a la confrontación cmpírica; hay mayor hacinamiento en el pabellón que registra el índice menor de mortandad por fiebre pucrperal. Relata Hempel: "Se acudió a varias explicaciones psicológicas. Una de ellas hacía notar que la División Primera estaba organizada de tal modo que un sacerdote que portaba los últimos auxilios a una moribunda tenía que pasar por cinco salas antes de llegar a la enfermeria: se sostenía que la aparición del sacerdote, precedido por un acólito que hacía sonar una campanilla, producía un efecto terrorílico y debilitante en las pacientes de las salas y las hacía así más propicias a contraer la fiebre puerperal. En la División Segunda no se daba este factor adverso, porque el sacerdote tenía acceso directo a la enfermería. Semmelwciss decidió someter a prueba esta suposición. Convenció al sacerdote que debía dar un rodeo y suprimir el toque de campanilla para conseguir que llegara a la habitación de la enferma en silencio y sin ser observado. Pero la mortalidad no decrecio en la División Primera"10.

Y, así, Hempel suma y sigue. El método científico se ha encarnado en Semmelweiss, en las décadas cuarta, quinta y sexta del siglo pasado, y avanza fiel a la contrastación empírica de sus hipótesis. Pero en la historia, la completa y entera historia, no se parece a la profiláctica descripción de Hempel; ésta es tan sólo el resultado de una óptica parcial, unilateral. No se podría

${ }^{9}$ Op. cil., págs. 75,76 y 77.

${ }^{10}$ Op. cit., pág. 18. 
advertir, tras la impecable e imparcial presentación positivista, el drama multifacético y sus actores centrales: la ruindad, la porfía, la locura, la muerte. En la perspectiva de Hempel, los hombre reales parecen el cuerpo en que se embosca el método científico para llevar a cabo sus designios epistemológicos.

7. Tratemos de dar color de vida al rosa pálido de la verdad positivista. Semmelweiss va cuesta abajo en sus conclusiones: a) Todo se centra en el Hospital General de Viena; b) La muerte parece haberse puesto a habitar en la División Primera de Maternidad; c) En esta división el tacto de las parturientas es realizado por estudiantes, mientras que en la otra lo es por comadronas. Semmelweiss permuta a estudiantes y comadronas y el índice de mortandad se invierte. Klin, a cargo de la División Primera, siente el golpe y se dispone a devolverlo. No habla a Semmelweiss, le odia. No le preocupan los senderos que Semmelweiss abre en la maraña de la muerte, sino su prestigio de director, su nivel, su investidura, su vanidad. A la ocurrencia intuitiva de su ayudante en el sentido de obligarlos a todos a lavarse las manos antes de los reconocimientos táctiles de las parturientas, incluido él, se niega de plano. Semmelweiss se encoleriza, se sale de madres, atraviesa sin destino las barreras establecidas por la escenografía académica. Al día siguiente, es destituido. Es el 20 de octubre de 1846. Celine contagiado del clímax amenazante de la tragedia, usa el lenguaje como un aguijón:

"En efecto, por muy alto que vuestro genio os coloque, por muy puras que sean las verdades que se expresan, ¿hay derecho a ignorar la formidable potencia de las cosas absurdas? La conciencia en el caos del mundo es sólo una lucecita preciosa, pero frágil. No se enciende un volcán con una vela. No se juntan tierra y cielo a martillazos. A Semmelweiss, como a tantos otros precursores, debió de serle horriblemente penoso someterse a los caprichos de la necedad... Donde Semmelweiss se estrello, es casi indudable que la mayor parte de nosotros habríamos triunfado por simple prudencia, por delicadeza elemental. Es como si hubiese carecido to lo hubiese descuidado) del más mínimo sentido de las leyes de la futilidad que regían en su época, en todos los tiempos por otra parte, sin las cuales la necedad es una fuerza indómita"11.

Mientras los rencores entraban en la fase latente de su existencia cíclica, Semmelweiss, a insinuación de Skoda - director del hospital y que le quiere bien-, parte entonces a un interludio veneciano. De parte suya, pues, se ha implantado la tregua; en cuanto a la fiebre, se despliega potente por los hospitales europeos, elevando un índice tras otro. Luego de dos meses, regresa a Viena justo a tiempo para asistir a una cita crucial con la revelación de la verdad, surgiendo envuelta en el ropaje de la muerte. Por efectos de una herida durante una disección, Kolletchka, el profesor de anatomía, ha muerto bajo los mismos síntomas de las víctimas de la fiebre puerperal. Era de los pocos, escasos en verdad, que apreciaban a Semmelweiss, y éste se siente dolorosamente afectado por su deceso. No obstante, el dolor ha venido a ser la experiencia a través de la cual la verdad se va a volver patente. El mismo Semmelweiss habla:

"Estaba todavía bajo la influencia da las bellezas de Venecia, vibrando por entero de las emociones artísticas que había sentido durante los dos meses pasados entre csas incomparables maravillas, cuando me dieron la noticia de la muerte del desdichado Kolletchka. Este acontecimiento me sensibilizó ex tremadamente y cuando conocí los detalles de la enfermedad que lo había matado, la noción de identidad de este mal con la infección puerperal de la que morían las parturientas se impuso tan bruscamente a mi espíritu, con una claridad tan deslumbradora que desde entonces dejé de buscar por otros sitios..."

\footnotetext{
${ }^{11}$ Op. cit., págs. 69 y 70.

${ }^{12}$ Op. cit., págs. 98 y 99.
} 
8. Se nos impone la necesidad de bosquejar siquiera tímidamente la figura de Semmelweiss y así explicar, de algún modo, su vocación por la verdad. Por lo que sabemos, es un obseso por el sufrimiento humano; mientras sus colegas han cedido a la rutina constante de la familiaridad con la muerte, él, que es, además, un rebelde innato, un apasionado, no lo puede tolerar. No es posible un modus vivendi conciliante entre su temperamento furioso y el sufrimiento. Desde que le drama se ha iniciado y tiene como protagonistas a dos intolerantes irreductibles - la muerte y Semmelweiss-el desenlace está ya decidido y los precipitará en un torbellino demasiado vertiginoso para timoratos. La fiebre se merecía largamente un oponente a la altura de las circunstancias; lo había estado buscando inútilmente en la academia de rostro grave y cariacontecido. Y nada. No había grandeza espiritual tras esa parodia.

Hasta que se aparece Semmelweiss:

"Mi querido Markusovsky, mi buen amigo, mi suave apoyo, debo confesarle que mi vida fue infernal, que desde siempre la idea de la muerte de mis enfermos me resultó insoportable, sobre todo cuando esa muerte se desliza entre las dos grandes alegrías de la existencia, la de ser joven y la de dar la vida"13.

Aquí está, por fin, el personaje a la medida de los acontecimientos que van a sucederse: atolondrado, impaciente, impetuoso, presto al éxtasis, ardoroso, en movimiento perpetuo, irremisible e inverosímilmente tocado por el dolor ajeno; en una palabra, un hereje generoso. Tiene todos los atributos que se requieren para ser envidiado, murmurado, odiado, perseguido; le basta aparecerse para que la ruindad latente reconozca en él su blanco ancestral. Como en la tragedia antigua, el destino ha urdido la trama con la maestría de un dramaturgo cósmico.

De esta trama implacable, el filósofo positivista no ve más que la forma general, unos cuantos hilos abstraídos de su composición entera. Así, su visión de cómo irrumpe la verdad resulta, de veras, demasiado simplista y carente de "ánima": "Hemos visto cómo, en su intento de encontrar la causa de la fiebre puerperal, Semmelweiss sometió a examen varias hipótesis que le habían sido sugeridas como respuestas posibles". Esto es, en lenguaje positivista, las contrastó. Pero... Łasí, tan simplemente?, ¿mientras el resto de sus colegas admiraba como el brillante Semmelweiss llevaba a cabo una demostración magistral y gratuita del modo de proceder de un científico? ¿Le vieron y dijeron: "dejadle, está contrastando unas hipótesis?". No, en absoluto. Más bien, hicieron todo de su parte para que este método ambulante de las ciencias fuera expulsado. En esta atmósfera adversa, en verdad irespirable, es la fuerza espiritual de un hombre la que llega al sacrificio. Y la verdad - hipótesis contrastada-, es sólo una parte de la historia. Según Hempel, los hombres de ciencia andan contrastando. De acuerdo a los hechos (hechos de los que el positivista es el adorador) los hombres de ciencia, además, andan impidiendo que se contraste nada, andan determinando como herejía oscurantista todo lo que no se adapta a la palabra oficial, andan persiguiendo y anatemizando, andan cuidando el prestigio; son, en una palabra, el más grande obstáculo de la verdad. Esto es lo que Celine quiere mostrar y lo que nosotros queremos enfatizar. Semmelweiss ha sido posible a pesar de la ciencia de su tiempo. Pero, no concluyamos tan rápidamente, que recién ha caído el telón del primer acto y hay que dejar que las palabras desplieguen toda su capacidad significante. Celine no nos deja abandonar el asunto todavía; tiene mucho más que decir. Tiene mucho interés en hacernos digerir toneladas de drama. Se ha parado ahora sobre el escenario (es entreacto) y agita los brazos imponiéndonos el silencio.

Oigámoslo:

"En lo concerniente a sí mismo, carecía de toda ambición; no poseía tampoco ese afán por la verdad pura que anima a los investigadores científicos. Puede decirse que nunca se habría lanzado

\footnotetext{
${ }^{13}$ Op. cit., pág. 104.
} 
por el camino de las investigaciones, de no haberle arrastrado una ardiente piedad por la angustia física y moral de sus enfermos ("era, en suma, un poeta de la bondad, más activo que otros"). Cuando se confrontan estas palabras del doctor Bruck con la asombrosa agudeza de que hizo gala Semmelweiss en el transcurso de sus sucesivos descubrimientos, es lícito preguntarse si la tibieza y el egoísmo no son, en resumen, los más grandes obstáculos del genio para la mayor parte de los médicos de talento. Resulta penoso pensarlo pero a lo largo de las peripecias de esta trágica y maravillosa aventura es imposible dejar de sentir como surge de nosotros tal hipótesis, referida sobre todo a esos momentos extremos de la investigación, muy cerca del descubrimiento, cuando la verdad se oculta bajo los "poco más o menos". El "poco más o menos" es la forma agradable del fracaso, la tentadora consolación...

Para rebasarlo la lucidez ordinaria no basta; necesita el investigador una potencia más ardiente, una lucidez penetrante, sentimental, como la de los celos. Las más brillantes cualidades del espíritu son impotentes cuando nada más firme y más sabio las sostienen. El talento solo no podría pretender el descubrimiento de la verdadera hipótesis, por que entra la naturaleza del talento el ser más ingenioso que verídico.

Ya habíamos presentido a través de otros caminos de la medicina que esas sublimes ascensiones hacia las grandes verdades precisas suelen proceder casi por completo de un entusiasmo mucho más poético que el rigor de los métodos experimentales, que, por lo general, son considerados como la única génesis. El método experimental es sólo una técnica, infinitamente preciosa, pero deprimente. Exige del investigador una dosis extra de fervor, para en ningún caso desfallecer en el desolado camino que obliga a seguir, antes de haber alcanzado el fin propuesto. El hombre es un ser sentimental. Fuera del sentimiento "no existen grandes creaciones..." 14 .

Ya no puede sino resultar claro en que equidistan Hempel y Celine; esforcémonos, no obstante, por hacer más categórico, tajante y definitivo el contraste, y volvamos a Semmelweiss, en 1847, cuando, a fines de año, se ha enterado de las circunstancias que han rodeado la desaparición de Kolletchka. Se precipitan y agolpan en su mente, como en un torrente, las ideas que han ido y venido tratando de desenmascarar el disfraz mimético de la enfermedad. Y todas viene a converger en los estudiantes de Klin, que practican la disección de cadáveres y luego reconocen por el tacto a las parturientas. Kolletchka se ha herido durante una disección y ha cnfermado mortalmente: ya no duda.

Los estudiantes transmiten la infección desde la materia cadavérica hasta las parturientas, por vía de sus manos. Como los gérmenes se resisten a la observación microscópica, Semmelweiss los asedia y sitia mediante el olláato y concibe la profilaxis. Está claro que lo que motivó su expulsión de la División de Klin está de nuevo en el tapete. Skoda, el director del hospital, usa su influencia y hace que se admita a Semmelweiss en la División Segunda, cuyo médico Jefe es Bartch.

9. He aquí, pues, de nuevo, a Semmelweiss en el Hospital General de Viena. Este recinto vuelve a ser el escenario del drama, el cual no demora casi nada en reiniciarse y continuar. El telón ha vuelto a subirse. Apenas aparece, Semmelweiss logra que los estudiantes de Klin pasen a la División de Bartch, intercambiándose con las comadronas. Y por vez primera, la muerte es obligada a bailar al son de Semmelweiss. El índice, en la División de Bartch, asciende al 27\%. A continuación, impone el lavado de manos con una solución de cloruro cálcico y el índice baja al $12 \%$, primeramente, y luego a un $0,23 \%$. Triunfo rotundo. La muerte ha sufrido su primera derrota. Pero, cuidado. Vieja que es, tiene viejos y fieles aliados y maniobras a destajo con las que

${ }^{14}$ Op. cit., págs. 101 y 102. 
desequilibrar la balanza. Y se reserva para el último acto la más alucinante de todas. Pero, no nos precipitemos, que recién estamos ascendiendo hacia el clímax.

El contrataque se desata en el hospital mismo y lo encabezan la institucionalidad médica, la ciencia oficial, la academia local. Todos en perfecta armonía, blandiendo la razón majestuosa y la santa indignación. Celine se deprime y estado de lasitud remata:

"En el corazón de los hombres sólo habita la guerra"15.

Con escasas excepciones, todos los médicos, agitados por Klin, arremeten contra Semmelweiss. Se atraen a los estudiantes (futuros celadores del saber oficial), se niegan al lavado de manos. Desde fuera, lo mismo: Amsterdam guarda silencio, en Edimburgo no entienden nada, la Sociedad Médica de Londres juzga poco convincentes los resultados de Semmelweiss, los italianos y los praguenses los desmienten. Klin goza. Todos aborrecen el intrépido inconsciente. Y en la impunidad inexorable del odio, se recrean y florecen el rencor, la envidia, la estrechez de miras. Todo coagula en una síntesis perfecta de envilecimiento.

Otra vez, cedamos el lugar a Celine. Está, no cabe duda, furioso a morir:

"Pero estos grandes burócratas no sólo fucron ciegos, desgraciadamente. Fueron bullangueros y mentirosos a la vez y, además, sobre todo, necios y estúpidos. Malvados para con Semmelweiss, cuya salud se derrumba frente a estas increíbles experiencias. De ahora en adelante ya no le será posible aparecer en el hospital sin ser cubierto de injurias, "tanto de parte de los enfermos como por los cstudiantes y los enfermeros". Nunca la conciencia humana se cubrió de vergüenza tan rotunda y descendió más bajo que durante estos meses del odio contra Semmelweiss, en 1849. Por supuesto que semejante estado de cosas en una ciudad universitaria no podía durar; en ese momento el escándalo, desmesurado desde sus orígenes, alcanzó tal amplitud que el Ministro se vio obligado a destituir por segunda vez a Semmelweiss el 20 de marzo de 1849.

A partir del día siguiente, prosiguiendo su causa en otro escenario, Skoda comunica a la Academia de Ciencia una nota expresiva de los resultados en todo concluyentes y absolutamente favorables a la teoría de Semmelweiss, que acababa de obtener por infección de fiebre puerperal experimental en un cierto número de animales. Y Hébra, aquella misma tarde, en la Sociedad Médica de Viena, declara que el descubrimiento de Semmelweiss presenta tal interés para el porvenir de la cirugía y de la obstetricia, que solicita de inmediato nombramiento de una Comisión para examinar, con toda imparcialidad los resultados que aquel ha obtenido. Esta vez las pasiones no conocen límites; se insultan, incluso llegan zurrarse en el recinto de esta severa sociedad. El Ministro prohíbe entonces que la Comisión se reúna, al mismo tiempo que ordena a Semmelweiss que abandone Viena lo más pronto posible. Todo esto fue dicho o escrito"16.

Parodiando la manera positivista, Semmelweiss recibió, por cada contrastación confirmadora, una expulsión. A cada hipótesis, siguió una dosis proporcional de oposición cerrada. Esta vez, el exilio se prolongará hasta agosto de 1865 y terminará de modo trágico. Entre 1849 y esta fecha, Semmelweiss permanece en Budapest, conociendo la agitación y la efervescencia políticas. Se mezcla, se precipita en lo mundano, juega a la frivolidad, se dedica a la equitación y al cultivo de las relaciones; practica de doctor. Todo este pasar sin mayores sobresaltos termina abruptamente con la guerra. Ya para entonces. la fiebre puerperal y el Hospital General de Viena están al fondo de la memoria, lejos, borrosos. La vida disipada, de una parte, y la precariedad traída por la guerra, han postergado y vuel to latente el drama. Por ahora, se mantiene subterráneo, adormecido. En una suerte de intermedio.

\footnotetext{
${ }^{15}$ Op. cil., pág. 115.

${ }^{16}$ Op. cit., págs. 120,121 y 122.
} 
10. No se crea, sin embargo, que el intermedio es sinónimo de calma. De veras, en esta historia espantable no hay descanso, ni por un instante. No hay, prácticamente, la posibilidad de paz. Hungría pasa de la anarquía a la dictadura. A esta última, Celine la califica de ávida y meticulosa. Pero, por sobre todas las cosas, lo que reina y campea es la miseria. Noche casi absoluta, dice Celine, que tiene una pluma particularmente afinada para describir el estado de las cosas, es un maestro para el retrato del submundo; es el buitre perfecto para la carroña de esos años dantescos. Se diría que es su ambiente. Se mueve en él con una intimidad y familiaridad francamente shocantes. ¡Cómo escarba y cómo sonire escarbando!, sabe que provoca arcadas y goza sabiéndolo, se trata de una catarsis incomparable.

Semmelweiss está arrinconado en una pieza de una calle estrecha, asediado por el hambre y il frío. Vende su mobiliario para subsistir. Yace aislado y débil. Cae en cl marasmo. No escribe ni se interesa. Ha descendido hasta el mínimo vital, peligrosamente próximo al colapso final. Después de todo, la muerte ha sido su camarada constante y no está sino prolongándose una amistad de años. Sobrevive y no sucumbe porque unos cuantos amigos llegan al sacrificio para ayudarle. Este hombre no vive para términos medios de ninguna clase: o se le adora o se le repudia. Hay hombres que no ahorrarán energía para dañarle, donde sea que lo encuentren; así como los hay (forzoso es reconocer que se trata de los menos) que renunciarán a mucho para apoyarle. iQue hombre, éste! Conocerle es verse impuesto a implicarse en cuanto él haga; no se podrá, en caso alguno, permitirse ignorarlo y hacer mutis. Toparse con él es, ni que decirlo, verse empujado a vivir experiencias límites, no se ha andado dos pasos a su lado, cuando ya está uno en un dilema. Donde va se tiene la seguridad de un entuerto incómodo, es lo que, en la antigua jerga de la impunidad, se denomina "una persona conflictiva".

Debemos atender a los vicios de significación del estilo de lenguaje. El conflicto aparece aquí como la cualidad o el atributo propios de un hombre, ocultando su naturaleza relacional. El conflicto es una relación y requiere, para ser, de al menos dos partes. Cuando falta uno de los términos requeridos, la frase "conflic tivo" resulta ser la expresión de una astucia de monólogo. Voy y determino "conflictividad" a mi antojo, con absoluta independencia de una relación efectiva con mis semejantes. Semmelweiss no tiene nada contra Klin, pero Klin da por sentado que todo cuanto Semmelweiss hace es un concebido intento de fastidiarlo. Para Semmelweiss, el asunto, todo el maldito asunto, es la fiebre puerperal y Klin no pasa de ser un títere de las circunstancias. Títere, porque no entiende nada ni tiene la más precaria conciencia de lo que está en juego. Todo lo que logra ver es que Semmelweiss le fastidia el trabajo, le fastidia la vanidad, le fastidia el buen pasar, le fastidia el prestigio y le fastidia la parcelita de la Primera División del Hospital General de Viena, año de 1849. Pero a Semmelweiss, en verdad, no le van ni le vienen esas cosas; Klin puede morirse si quiere, esfumarse en una nube de vapor o irse a algún continente exótico. Y nada de eso cambia el propósito que él se ha impuesto. Definitivamente, no lo cambia.

Semmelweiss no tiene por designio echarles a perder el negocio; o sea, no se propone desatar conflicto alguno. La verdad, en cambio, es que el conflic to se desata solo, sin ayuda de Semmelweiss. Está allí, listo a precipitarse cuando la ocasión la pinten calva. Para Celine, tiene que ver con la naturaleza humana. Semmelweiss podrá ser el dispositivo disparador, el gatillo, si se quiere, pero no pueden achacársele ni la existencia ni la naturaleza del conflicto.

11. Volvamos al intermedio, que su fin se aproxima. Retengamos de los actos anteriores que las cosas no ocurren de acuerdo a la ingenua y dañina superstición cotidiana. Esto de que la verdad siempre triunfa y de que la justicia tarda pero llega, no pasa a ser consolación barata; se cree - porque se trata de una creencia- que hay en los hechos una suerte de latente trayectoria de acuerdo a ciertos valores fijos. Se pretende que basta con que las cosas ocurran para que, en el tiempo, las anude la lógica del espíritu; se podría hablar de un determinismo moral. Celine (ni qué 
decirlo) no suscribe semejante doctrina. Esto de la vocación humana por el bien le resulta simplemente irreal. Pongámoslo de este modo; si hay una lógica moral inmanente en los hechos, los hombres parecen actuar exactamente en sentido opuesto. Si hay tal lógica, no son los hombres sus agentes; y, entonces, forzado entre la maldad humana y una lógica cósmica del bien, el mundo no puede ser sino experienciado como absurdo. En suma, aquí reside la inverosimilitud de los humanismos y, por supuesto, su paradoja: la existencia real e indesmentible de la maldad humana.

Retengamos, también, de los actos anteriores, que la verdad ha estado tratando de seducir a los hombres y se ha llevado un chasco tras otro. En realidad, no ha logrado impresionar. Es tal la multitud de impostores que se protegen y ufanan de consagrarse a ella a diario que cabe preguntarse donde está cl artificio; si es que hay artificio, y si es que los papeles están confundidos; si, en una palabra, todo el asunto fue mal montado y está resultando un enredo grotesco.

Pero no pretendamos comprender con arreglo a nuestros viejos vicios categoriales. He aquí que Semmelweiss está postrado, miserable y hambriento, aplastado y en un rincón. Y no cabe pensar que algo anduvo mal en el montaje. Quitemos la plañidera plegaria humanista y queda claro que Semmelweiss forma parte de un círculo perfecto, incluso armonioso. Y para que el calificativo de "armonioso" tenga aquí sentido, hay que despojarlo de la manía moral esteticista; porque de acuerdo a una vieja trilogía mental, hay una armonía entre lo bueno, lo verdadero y lo bello; y la fealdad, como el mal y la falsedad, son cosa contrahecha y deforme, grotesca y chocante. Sin embargo, por todo lo que se sabe, el infierno cs una entidad coherente y armoniosa: no hay en él almas bellas o espíritus inocentes. Si los hubiera, esto revelaría un grave error de construcción en la arquitectura del universo. Hay, pues, una armonía del mal.

Semmelweiss postrado no es, en consecuencia, un error del mundo, una mutación inexplicable o algo que escapó a la ingeniería del Bien. Es, en verdad, una pieza del rompecabezas, una parte perfectamente coherente de la existencia.

12. Pongamos atención en la manera como el drama irrumpe de nuevo, con la violencia requerida para conducirnos, sin respiro, hasta el clímax. La depresión en la que se ha sumergido Semmelweiss es demasiado honda como para que cualquier cosa lo ponga en movimiento. ¿Qué minucia cotidiana, qué frivolidad, se bastarían para seducirlo? Por ello, no se interesa en absoluto cuando, tiempo después, y a instancias de Skoda, se le ofrece una puerta. No. Este trágico se merece una rentrée en forma, un incentivo lo suficientemente elocuente como para motivarlo. Se verá, en lo que viene, qué es lo que tiene que ocurrir para que venza su lasitud y vuelva a la escena. Es, de veras, demasiado decidor. Cedamos la palabra a Lois Ferdinand Celine:

"Así, arrastrando los días, rehuyendo el esfuerzo, había dejado de esperarlo todo, cuando un acontecimiento fortuito le reinstalo en su destino.

— $i$ Es usted el doctor Semmelweiss, antiguo ayudante del profesor Klin? — le preguntó cierta mañana un visitante.

- Traigo un mensaje para usted. Un mensaje penoso, pero favorable a la causa que usted ha defendido. Los hechos son estos: el profesor Michaelis, de Kiel, se ha suicidado recientemente en circunstancias muy particulares; yo era alumno suyo y conocía sus ideas, sobre todo esa idea obsesiva que le ha conducido al suicidio. No hace mucho asistió en el parto a una de sus primas, la cual sucumbía pocos días más tarde a consecuencias de una infección puerperal. Tan grande fue el dolor de Michaelis, tan espantosa su desesperación, que emprendió una investigación minuciosa y muy profunda sobre su responsabilidad en esta desgracia. No tardó mucho en convencerse de que era por entero responsable, ya que en los días anteriores precisamente había cuidado a algunas 


\section{EL LADO OSCURO DE LA CIENCIA}

mujeres atacadas de fiebre puerperal, sin adoptar después ninguna de las precauciones que usted ha indicado y que él conocía desde hace mucho tiempo. La obsesión que le agobiaba se hizo un día tan punzante, tan intolerable, que el profesor se lanzó bajo las ruedas de un tren..."17.

Dejemos que el relato de Celine dé lo suyo. En cuanto a nosotros, insistamos en algo que ya resulla, de todos modos, evidente. Por desafiar a la muerte y a sus cómplices vivientes, Semmelweiss ha recibido su parte. En la forma de miseria, hambre y ruina, la muerte le ha estado rodeando sin compasión. Debe reconocerse, no obstante, que este Semmelweiss en Budapest, abatido y en letargo, ya no está a la altura del desafío audaz. Es seguro que, en la primera parte de este combate infernal, Semmelweiss no contó con los hombres, teóricamente dignos de amor y renunciación, formarían fila junto a la enfermedad y la muerte. Esta complicidad apocalíptica, prima hermana de la indiferencia o el desprecio por el sentimiento ajeno, lo cambia absolutamente todo. Por de pronto, coloca a Semmelweiss (como a cualquiera) en una encrucijada, cuya expresión espiritual termina rodando hasta la esquizofrenia: se quiere hacer el bien, se quiere ayudar, se quiere reducir al sufrimiento, se quiere mediatizar la impotencia del hombre frente a la enfermedad. Esto es a lo que apunta la tensión del alma. Pero este deseo ferviente de humanidad habrá de hallar su principal sbstáculo en los hombres mismos. La conciencia de esta divergencia tuvo que dejarle huellas y Ilagas; sólo esta conciencia, - conciencia de escisión-, puede explicar la locura final, tanto como a que ha teñido este drama desde un comienzo. Es crucial comprender los signos de locura y muerte que rodean el destino de Semmelweiss, y que rodean el entero asunto. Fijémonos en este tro personaje inverosímil, Michaelis, y su sino de dolor y locura la moraleja diría así: todo amor lesmedido por los hombres conduce a la autodestrucción. Toda indiferencia en cambio, asegura a sobrevivencia. ¿Qué impulsa a este Michaelis a guardar tamaña fidelidad consigo mismo? ¿Qué ‘ntido de la justicia es éste, que no tiene otra salida que el suicidio? ¿Qué clase de fidelidad y ioherencia son éstas, y por qué imponen semejante sacrificio?

Digamos, para intentar dar con una clave, que se ha requerido de este sacrificio y de la corte le sus circunstancias para que Semmelweiss retorne a la latencia. Otra vez, la muerte oficia de mensajera y desafía al iluso que la ha enfrentado tiempo atrás. Movido como por un resorte : lúrico, nuestro hombre irrumpe de nuevo en la escena. Esta vez nadie se irá de sus asientos, nadie odrá despegar los ojos, a nadie le estará permitido eludir lo que viene hasta que nos hallemos de leno en el mismísimo desenlace. Esta marea de compromiso e implicación es lo que la lógica ositivista no sería capaz de recoger; ante esta dimensión recalcitrante del drama, la epistemología scolástica resulta pura impotencia.

13. También resulta crucial atender al modo como se van encadenando los hechos. Hay algo ¿e extraño maridaje entre lo necesario y lo fortuito en ellos. Porque es claro que Michaelis no se a quitado la vida para que Semmelweiss resurja de su anestesia vital. Y, sin embargo, tal es lo - ue va a acontecer. Observando el masivo rechazo que las ideas de Semmelweiss han provocado, - puede uno reprimir la conclusión de que Michaelis es una franca excepción. Colocado uno en i situación de esa medicina oficial, no se tenían más que dos caminos: uno, retroceder de toda videncia e ignorar, impúdicamente y mañosamente, protegiendo la fortaleza del saber estableci$\therefore$; el otro, inclinarse ante la evidencia y vérselas con la conciencia de culpa; pues, habiendo -norado intencionalmente, se ha sido abiertamente criminal. El primero de estos caminos lleva al onformismo fanático, el segundo, al autosacrificio. El primero supone una conducta de conserxión, el segundo una de ruptura.

El autosacrificio de Michaelis es, en consecuencia, una resultante congruente. Habría que . stenerse a pensar en esta ligazón entre hiperconciencia lúcida y autosacrificio. Hay, todavía, otro

${ }^{17}$ Op. cil., págs. 134 y 135. 
aspecto de la cuestión que termina siendo bastante difícil de comprender, cual es el de la evidencia de la verdad y la supuesta vocación humana para reconocerla y rendírsele. Es problemático sostener que esa ciencia oficial viera las ideas de Semmelweiss bajo la forma de evidencia de la verdad; más bien, no la veían y tenían por firme lo antes establecido. Esto que es nuestra evidencia no parece haberla sido para ellos. Pero, ¿cómo explicar su maldad? Se trataría de una maldad ejercida en el nombre del Bien, la Verdad y la Ciencia Oficial. Este hecho, que induce tanta perplejidad a los pensadores de los fenómenos sociales, aparece constantemente en la historia de las ciencias, las religiones, las ideologías y las creencias en general. Pocos, en verdad bastante pocos, han acertado en la revelación del sentido de esta inconsistencia. Por el contrario, la multitudinaria literatura circulante sobre el tópico puede ser reducida a una operación racionalizante, destinada a disolver o enmascarar esta franca y ostensible contradicción.

Estamos, en efecto, ante este hecho: con una mínima excepción, todos los hombres de ciencia de la época no ven en Semmelweiss a la evidencia de la verdad encamada. Muy por el contrario, ven en él a un intruso, un audaz y un loco agresivo; en una palabra, un sujeto peligroso. Cabe concluir que con absoluta independencia del hecho de que Semmelweiss fuera o no lo que la ciencia oficial ve en él, esta procederá a reaccionar en su contra conformando a su amaño una imagen afín y proporcionada. Se llegará a presentar las cosas de modo que la persecución al hereje esté santificada y no provoque remordimientos de ninguna especie.

Hasta aquí, - al reiniciarse el drama - Semmelweiss no se ha puesto a la altura de la imagen terrible que de él han elaborado. Pero hacia el final se volverá contra los hacedores de imágenes y hará que la invención se vuelva concreción pura y dramática.

14. Hacíamos ver que el ánimo de Semmelweiss en Budapest es francamente depresivo y cuesta abajo. No se iba a romper ese círculo con cualquier minucia. Después de tanta inquina (y todavía no se ha desparramado toda la que habrá de surgir) y tanta agresividad, fue absolutamente necesario algo tan o más intenso para que volviera a resucitar este rebelde dolido de la incomprensión. El autosacrificio de Michaelis lo pone de pie. Ahora los que creen que el asunto está oleado y sacramentado, que el audaz ha sido apartado para siempre jamás, van a llevarse un chasco a la altura de sus intrigas. Consuela bastante saber que Semmelweiss va a fastidiarlos de modo que no puedan asegurar la tranquilidad y el orden establecido de sus existencias; porque en cuanto a la Verdad y la Justicia... bueno, ellas acostumbran a burlarse de lo contemporáneo y prefieren aparecer después, cuando el drama ha llegado a la consumación y no hay ya quien violente o trastoque el sentido de su desenlace. Celine se regocija de trajinar los velos de la Verdad y mostrar el carácter postrero y extemporáneo de la Justicia. Ahora bien, ha de quedar claro que la expresión "justicia postrera" es una expresión de términos contradictorios. Si es postrera, no es justicia. De la justicia habría que decir (y el caso de Semmelweiss así lo testimonia) que llega siempre atrasada, esto es, cuando ya no tiene ninguna importancia su llegada. Amén de postrera, en el caso de Semmelweiss, habrá de resultar descarada y burlescamente póstuma.

Pues bien. Merced a una recomendación de Skoda (que no le ha olvidado y es una especie de guardián celestial suyo), Semmclweiss logra un trabajo intermitente en la Maternidad de San Roque, en Budapest. Birley, su director, le acepta con la promesa formal de no insistir en sus experimentos. Este personaje, Birley, resulta ser una suerte de hombre medido, tibio; no hará nada por dañar materialmente a Semmelweiss, a quien cree en la razón; pero, tampoco, hará nada por desafiar la normalidad de su institución. En tanto Birley existe, mantendrá y prevalecerá un status quo temporal. El propio Semmelweiss, paradojalmente calmo, entrará en una especie de tregua preparatoria de nuevas y más horribles tempestades; de esta tregua, surge la redacción de su obra máxima: LA ETTOLOGía DE LA FEBRE PUERPERAL, cuya puesta al día le tomará unos cuatro años. En el lapso, intenta contactos con diversos hombres de ciencia y diversas academias científicas, y la 
respuesta es siempre, exactamente, la misma: silencio. ¿Ha podido la Verdad, alguna vez, provocar igual unanimidad? Ni siquiera alguien se molesta en criticarle. Si en alguna parte sus ideas son meramente aludidas, todo ello ocurre en el más estricto secreto y la más celosa autocensura.

Celine nos cuenta que, a la altura de 1855 , las cosas han mejorado un poco desde el punto de vista material. Semmelweiss gana una suma pequeña pero útil para mantenerse. Esta es la atmósfera de la historia hasta que, abruptamente, Birley muere y Semmelweiss le sucede en la dirección de la Maternidad de San Roque. Y aquí, exactamente en este punto, año de 1856, el rebelde dormido desenvaina la espada y toma la iniciativa.

Nadie podría calificarnos de melodramáticos y de exagerados si insistimos en advertir las circunstancias que rodean la trama y su estrecha familiaridad con la muerte. Con ella a la vista, este Semmelweiss inverosímil se despliega a sus anchas. Recordemos que es la muerte masiva de parturientas lo que lo lanza a la búsqueda; recordemos que la muerte vestida de guerra y miseria lo sigue a Hungría; recordemos que la muerte de Michaelis lo saca del marasmo y la muerte de Birley, ahora, lo pone a la batuta y le da la iniciativa. La muerte misma no puede evitar dar estas ventajas a este irreductible enemigo suyo. Ahora, se irán mano a mano hasta el final. Al reiniciarse las hostilidades, Semmelweiss comienza arremetiendo directamente contra sus aliados académicos.

15. Celine nos obsequia reproduciendo algunos párrafos de un panfleto de Semmelweiss "Carta abierta a todos los profesores de Obstetricia":

"Me habría gustado mucho que mi descubrimiento fuese de orden físico, porque se explique la luz como se explique no por eso deja de alumbrar, en nada depende de los físicos. Mi descubrimiento, ay!, depende de los tocólogos. Y con eso ya está todo dicho...".

“Asesinos! llamo yo a todos los que se oponen a las normas que he prescrito para evitar la tiebre puerperal".

“ ¿Contra ellos, me levanto como resuelto adversario, tal como debe uno alzarse contra los partidarios de un crimen! Para mí, no hay otra forma de tratarles que como asesinos. Y todos los yue tengan el corazón en su sitio pensarán como yo. No es necesario cerrar las salas de la maternidad para que cesen los desastres que deploramos, sino que conviene echar a todos los iocólogos, ya que son ellos los que se comportan como auténticas epidemias, etc..."18.

Todos entienden perfectamente que se trata del reinicio de las hostilidades y de una declara¿ión de guerra en forma. Ha cambiado el escenario, pero el odio que va a desatarse es el mismo, "eco ampliado de aquel otro odio". Hay que tener en cuenta las vicisitudes por las que ha pasado ¿sta ciudad para comprender la amplificación que alcanza el resentimiento. En el hospital mismo, por obra de una operación obvia de solidaridad, todos se vuelven contra Semmelweiss, se glutinan espontáneamente, se coagulan, se cohesionan. Por las cosas que van a llevar a cabo bien aldría llamarlos "la fraternidad de las sanguijuelas"; lo que van a estar dispuestos a hacer resultará :anl evidentemente desproporcionado que cabrá interrogarse sobre lo que está verdaderamente en :uego. He aquí una lista de las acciones de los buenos señores indignados en el nombre de la acrosanta Verdad, la infalible Ciencia y el saber Oficial:

—Desobedecieron, deliberadamente, las prescripciones aconsejadas por Semmelweiss.

- Boicotearon el abastecimiento del hospital.

- Impidieron el ensayo experimental de las ideas de Semmelweiss...

\footnotetext{
${ }^{18}$ Op. cit., págs. 141 y 142.
} 
Y como broche de oro - según lo indican todas las presunciones-infectaron a parturientas para "demostrar" la infundada pretensión de Semmelweiss. ¡ Hasta este extremo fueron capaces de llegar! Estamos aquí, indudablemente, ante una desproporción desconcertante. Porque Semmelweiss ha puesto en práctica sus prescripciones; ha publicado un panfleto, rudo de veras. Pero, no ha puesto en juego la vida de sus pacientes. Estos otros (sus enemigos) parecen actuar creyendo que, puesto que representan y encarnan a la Ciencia, les está permitido hacer de cualquier cosa un medio. Es tan sagrado e intocable lo que defienden, que se sienten autorizados para sacrificar vidas en el nombre de la vida. Tienen por lin aplastar al atrevido rebelde y con tal de hacerlo urdirán tejidos de insondable ruindad. ¿Cómo ha sido posible? ¿Qué los ha conducido hasta el límite?

Por experiencia, sabemos que en determinadas circunstancias (ni tan excepcionales ni tan intrascendentes como se piensa comúnmente), las cosas ocurren escapando al control de sus protagonistas y se precipitan como si las determinara una invisible necesidad. Extendidas supersticiones llaman "destino" a este género de ineluctabilidades. Los entendidos incluyen estos fenómenos en los estudios de psicología de las masas, de las multitudes, del colectivo o social, pues se trata de conductas grupales. Cualquiera sea la perspectiva, conformémonos con indicar que, de pronto, el saber alcanzado por el desarrollo de la ciencia adopta la forma de la intocabilidad y sus celadores oficiales llegarán al crimen por mantener su rigidez; en estas ocasiones, la ciencia se vuelve dogmática, oscurantista y fanática, y perseguirá implacablemente toda instancia crítica

16. Rodeado de furia mezquina, Semmelweiss va enajenando toda simpatía y se queda prácticamente abandonado. Es un monarca sin poder, porque nadie acata sus decisiones en el hospital. Cercado, concibe, junto con un único amigo que le cree, una expedición a París, cuya tradición iluminista podría abrirse generosamente a sus ideas y, eventualmente, propagarlas. El 13 o el 18 de marzo de 1858 (los biógrafos no se han puesto de acuerdo), Arneth, su amigo, parte a París y permanece allí esperando que la Academia dedique algunas reuniones sobre la fiebre puerperal; las sesiones se producen, en efecto, pero con un decepcionante resultado. El último esfuerzo por vencer el sitio en torno suyo ha sido hecho y se ha frustrado. Celine ubica en este punto el inicio de la locura de nuestro Semmelweiss.

Sus clases se convierten en una sistemática diatriba; en las paredes de la ciudad aparecen sus manifiestos insolentes, advirtiendo a la población del peligro que significan los obstetras y las comadronas. Ha dado el paso que lo coloca más allá de lo que la normalidad mental admite. Comete la torpeza de no conceder la derrota, de no transigir diplomáticamente, de no abrirse a la racionalidad, de no hacer algo por descargar la ya sobrecargada tensión de la atmósfera. Es fácil ver que no tiene en mente qué hacer y, más bien, deja que el curso de los hechos y las situaciones se imponga. Por dentro, libra una insoportable batalla en la búsqueda de un sendero que rompa la maraña. Es necesario decir que la guerra se va a ir interiorizando en su alma; la introyecta y le imagina vicisitudes fantásticas, esgrimiendo su furia en irreales combates inconscientes.

Cedamos una vez más, el lugar a Celine:

"indudablemente, a partir de este momento se le habría destituido de su cargo, si su progresivo agotamiento no se hubiese adelantado a esta inútil sanción. En efecto, pronto las palabras que pronunciaba fueron incoherentes y, con mucha frecuencia, carecían de sentido. Su cuerpo se inclinó con un nuevo modo de andar, a trompicones, ante los ojos de la gente, pareció avanzar tambaleante por un terreno desconocido...

Le sorprendieron dispuesto a horadar las paredes de su habitación en busca, según él, de grandes secretos allí enterrados por un sacerdote conocido suyo. En el espacio de algunos meses, sus rasgos se surcaron profundamente de melancolía y su mirada, perdiendo el apoyo de los objetos pareció perderse más allá de las personas... Rápidamente se convirtió en el fantoche de sus propias facultades, tan potentes en otro tiempo y en la actualidad desencadenadas en el absurdo... 


\section{EL LADO OSCURO DE LA CIENCIA}

Fue sucesivamente poseído por la risa, por la venganza, por la bondad, del todo, sin orden lógico, cada uno de sus sentimientos influyéndole por su cuenta, como tratando sólo de agotar las fuerzas del pobre hombre aún más por completo que el frenesí anterior... Avanzando por este dédalo movedizo, despiadado, por la demencia, se le aparecieron un Michaelis sangrante, cargado de reproches; un Skoda desmedido, grosero; un Klin furioso, acusador, empalidecido por todos los odios de un mundo infernal, y Seyfert y también Scanzoni... Cosas, gentes, más cosas, corrientes cargadas de terrores indecibles, formas imprecisas le arrebataban, confundidas con recuerdos del pasado, paralelos, entrecruzados, amenazantes, desvaídos... También, en torno suyo lo real, lo banal, se intercalaban con lo absurdo con un maleficio de su espíritu sin límites. Las mesas, la lámpara, sus tres sillas, la ventana, los más ncutros objetos, los más usuales en su vida cotidiana, sc envolvían en un halo misterioso, en una luz hostil. Ninguna seguridad en lo sucesivo dentro de esta fluidez grotesca, en la que se licuaban los contornos, los efectos y las causas. A esta habituación, desplazada por un enloquecimiento utópico y ucrónico, retornaron los visitantes fantásticos... Cada uno de ellos proseguía la polémica de otros tiempos; argumentaba abundantemente, con lógica a veces y, con frecuencia, hasta después de que hubieran partido. Pero, casi siempre, estas alucinaciones terminaban en violencias. Demasiadas sombras burlonas y mentiroits rodeaban su lecho, demasiadas para que viese a todas, cara a cara. ¿No las oía acaso conspirar is sus espaldas, enemigas trapaceras? Y su frenesí se asfixiaba cuando huían; muchas veces se lanzaba tras ellas por la escalera, incluso por la calle, persiguiéndolas..." 19 .

Es tan vívida la descripción que Celine nos da que huelga toda reiteración literaria. Estas ríginas de Celine éstán entre las más magistrales de este texto suyo sobre Semmelweiss. Entre us virtudes, resalta esta percepción tan aguda de los rasgos y rincones de la locura de nuestro rofeta. La identificación que logra con su personaje es tan perfecta que podría decirse que ha sido sstigo presencial. Si no supiéramos que le separan de él unos ochenta y tantos años, que nace - uando ya han pasado casi tres décadas del fin trágico de Semmelweiss, se diría que ha estado allí usmeando y padeciendo lo suyo en el instante de ocurrir las cosas.

17. Tenemos pues, que Semmelweiss ha perdido toda cordura. Está extraviado. Está loco. - odo esto, mientras las ratas celebran la caída chillando a coro y las parturientas continúan siendo icrificadas al conformismo con el saber institucionalizado. Hay que retener este hecho esencial: fiebre puerperal sigue a sus anchas, oficialmente tolerada. Siguen muriendo las parturientas. No perdamos de vista, no sea que nos enredemos en detalles menores. En tanto sigue siendo así, immelweiss está loco sin vuelta; él, el único que sabía como proceder para hacer poner en $\therefore$ irada a la muerte. Y la Verdad, la bien amada y siempre deseada, se ve impedida, al parecer, initivamente. Con Semmelweiss enfermo de obsesión, se nos ha escurrido de las manos y puede i no haya ya nadie que la encarne como corresponde.

Y Semmelweiss, loco y todo, no puede sacarse de encima la posesión del secreto. Él tiene la inula para evitar tanto dolor, tanto sufrimiento. ¿Por qué a nadie la interesa? ¿Por qué nadie se .e cargo? ¿Por qué nadie ve? ¿Por qué tantísima ceguera? Mientras, con Semmelweiss falto de $\therefore$ ón, todos se limpian las manos y prosiguen sus existencias sin asomo de culpabilidad. Asunto -ninado. Para nuestro enfermo de generosidad, no obstante, no hay paz; ni siquiera la de la - onciencia. Allí está lidiando con las apariciones que lo acosan. Ahora que, al parecer, ya no irá librar combate real alguno, enhebra guerras imaginarias en los mínimos metros cuadrados \&u cuarto. Está enfermo de impotencia. Soñó acaso que la verdad se hacía presente como $\therefore$ umbramiento, no como padecimiento; ha de haberla creído hermana del placer. Supuso que,

\footnotetext{
Op. cit., págs. $151,152,153,154$ y 155.
} 
portándola, todos concederían, todos reconocerían, todos recordarían, todos se entregarían al develamiento. Helo aquí perplejo, porque nada ocurrió de acuerdo a las maravillas relatadas en los textos de las hazañas del hombre. Él no hacía más que esto, que, a todas luces, era un bien: presentar un camino para aliviar el dolor de tantas mujeres. Todo lo que tuvo por respuesta fue el odio sistemático, la estúpida incomprensión. Vaya reconocimiento.

Volvamos sobre algo que ya habíamos precisado y tratemos de enfatizar cuánto nos importa. Ni en el reinado de la locura, Semmelweiss logra sentirse aparte del asunto. La fiebre puerperal, la muerte, que ha sido su obsesión permenente, no le van a permitir respiro hasta el instante final. Lo cierto es que, incluso desquiciado, no ha dejado de rondarle el sentimiento de tener la clave en la mano y no poder con todo, hacerla realidad. La lúcida conciencia de esta impotencia preside su locura.

El drama ha seguido hasta aquí una trayectoria peculiarísima: primero se ha desplegado en el escenario vienés; luego, en el escenario húngaro. En ambos escenarios, las cosas han tenido amplia resonancia política y ha habido mucha participación colectiva. Repentinamente, ha sufrido un embotellamiento, se ha estrangulado, se ha convertido en una débil huella y ha tomado residencia en el alma de Semmelweiss. Allí se ha posesionado de su dueño y campea a sus anchas. No cabe duda de que es demasiada carga para un solo hombre, por más que se trate de un ser generoso y sensible. Eso es lo que la gente, ajena, ve pasar por las calles de Budapest: es Semmelweiss, que va rumiando el drama generalizado por sus huesos y vísceras. Eso explica lo encorvado y trastabillante que anda: es la torpeza del absurdo. Si resulta grotesca su figura, debe decirse que, ante todo, es retrato fiel del daño recibiło por forjar ilusiones y pretender remover un poco del dolor que penetra en el mundo de punta a cabo. Semmelweiss loco es, claramente, lo que los hombres han hecho de él; los representa cabalmente.

Hagamos un raconto al estilo acaćémico. Ha de resultar claro ya que la dificultad de la interpretación de Hempel acerca del procedimiento de las ciencias, reside en esto: resulta estrecha, se queda corta y se convierte en fórmula escolástica. Su certeza relativa descansa en el reconocimiento de que el hombre de ciencia procede buscando contrastar hipótesis que ha levantado sobre determinados hechos; esto, que parece verdadero, queda como mera descripción formal en la medida en que Hempel no da lugar al hecho de que no sólo hay ciertas hipótesis previas a la investigación sino que, además y principalmente, hay determinadas concepciones y creencias prevalentes en determinadas épocas, prejuicios e ideas fijas que dan todo su sello a la actitud cientílica y la caracterizan peculiarmente. La lógica de la contrastación de la que Hempel habla es igualmente una fórmula vacía, la mera forma de las determinaciones que conforman las "verdades" de la ciencia y que ignora, obvia o subestima, factores cruciales como la convención, el prejuicio, la creencia establecida, la inercia de las ideas, la persecución de las nuevas interpretaciones. La lógica positivista de la ciencia resulta ser, así, una forma sin contenido, algo que no se encarna y configura en las vicisitudes rec les de la ciencia. Es la historia de la ciencia, la ciencia en su despliegue, la que presenta y desarrolla el conjunto de rasgos que moldean la verdad científica; frente a esta historia real, la lógica de la ciencia termina siendo una lógica inerte, fría, carente de contenido, interesada en no mezclar la verdad sacrosanta con la existencia práctica de la ciencia. Esta existencia contiene el genio, la imaginación, la grandeza del pensamiento, pero igualmente la vanidad, la cobardía, la ruindad, la persecución de las ideas, el fanatismo, el retroceso, el mito, la tergiversación.

18. Bien. Ahora es el final. El drama, luego de fijarse y residir en el alma del que se permitió iras que no conocen clemencia ni descanso, va a sufrir una explosión digna de remate apocalíptico. Luego de rumiarlo y girarle alrededor, Semmelweiss va a arrojarlo de vuelta a los demás, para que compartan siquiera el disgusto de una escena chocante. 
Hagamos un esfuerzo último y pongámonos a imaginar esta escena: salta de su cama y se precipita escaleras abajo, ojos inyectados y brazos aleteando; corre por las calles, desaforado, profiriendo alaridos indefinibles. La gente que pasa, se vuelve para mirarlo. Es el loco Semmelweiss. Continúa corriendo, la boca se le llena de espuma, tropieza, se levanta y sigue, choca con la gente, las aparta a manotazos y blasfemias, maldice furioso, obsequia miradas amenazantes. De seguro, va a alguna parte en especial porque corre con la determinación de quien está absorbido por una idea fija. ¡Caramba!, ha penetrado al recinto de la Facultad y continúa su agitada maratón. Casi podemos presentir lo que se avecina ( $\mathrm{V}$ Va cometer alguna locura!, lo cual es lo que se espera de un loco). Se precipita en una sala de estudiantes practicando con un cadáver, empuja, violenta, da codazos, se abre paso y se apodera de un escalpelo, todo ésto a la vez que aúlla, vocifera, enronquece, se le hincha el rostro, se le descompone el gesto, brama. Se abalanza sobre el cuerpo sin vida y lo despedaza a cortes furiosos y reiterados que se disparan sanguinolientos y pútridos, por entre rostros y manos; dirige ahora el escalpelo hacia sí mismo y se hiere sin compasión. Lo rodean, tratan de impedirle que se dañe, lo reducen. Y fin de la escena.

Skoda se lo lleva a Viena. ¿Qué diremos de Skoda, este inverosímil de la fidelidad? En cuanto llega con él, tiene que internarlo en un manicomio; allí Semmelweiss agonizará durante tres semanas. El 16 de agosto de 1865 , el autosacrificio llega a su fin.

Celine habla: "Ios progresos de la infección fueron bastantes lentos, bastante minuciosos para que, en el camino del reposo, ninguna batalla le fuese perdonada. Linfangitis... Peritonitis... Pleuresía... Cuando llegó el turno de la meningitis, entró en una especie de parloteo incesante, en una interminable reminiscencia, a lo largo de la cual su destrozada cabeza pareció vaciarse en largas frases muertas".

"No se trataba ahora de aquella infernal reconstitución de su vida al nivel del delirio de la que en Budapest había sido el actor tiranizado, durante las primeras etapas de su locura. En la fiebre se habían consumido todas sus energías trágicas. Únicamente pertenecía a los vivos gracias al impulso formidable de su pasado".

"En la mañana del 16 de agosto la Muerte le agarró por el cuello. Se asfixió. Los hedores de la putrefacción invadieron el cuarto. Verdaderamente era ya tiempo de que partiese. Pero se aferró a nuestro mundo tanto como es posible con un cerebro quimérico en un cuerpo desgarrado. Parecía desvanecido, extraviado en la sombra, cuando, muy cerca del fin, una rebelión última le devolvió la luz y el dolor. De repente, se enderezó sobre la cama. Tuvieron que volverle a tender. ¡No! ¡No! gritó varias veces. Es como si en el fondo de este hombre no hubiese existido indulgencia alguna para la suerte común, para la Muerte, y ninguna otra posibilidad en él que una inmensa fe en la vida. Aún le oyeron llamar: ¡Skoda!, a quien no había reconocido. Entró en la paz a las siete de la tarde"20.

19. Reconozca, estimado lector que, a menos que la suerte de Semmelweiss le parezca merecida, convendrá conmigo en que se trata de una cosa espantosa. Es casi seguro que se le saldrán espontáneamente expresiones del tipo de "iqué increíble! ¿cómo es posible?". Ahora bien, es mi deseo que beba todavía un último trago amargo y comparta conmigo algo del sabor de la maldición que Semmelweiss nos ha brindado.

La indignación que nos asalta — déjeme decírselo-es, ante todo, una indignación que resulta de la perspectiva distante desde la cual contemplamos la tragedia. Lo que trato de decirle puede resultar más claro de la mano de esta distinción, que le propongo: efecto de proximidad, efecto de distancia. Dicho ahora en términos de esta distinción, nuestra indignación es producto del efecto

${ }^{20}$ Op. cit., págs. 162 y 163. 
de distancia. O sea, nos indignamos en la medida de nuestra ausencia; se puede, también, poner así: terminada la batalla, aparecen generales a granel. Henos aquí colocándonos condecoraciones, charreteras e insignias. Y mi argumento definitivo es éste: si usted, o yo, o cualquiera, hubiésemos vivido en la época de Semmelweiss y en los lugares en que él se debatió contra la muerte, habríamos sido, de hecho, enemigos suyos y no sus aliados. Sí. Ya sé que usted me dirá que no, que de veras se habría colocado de su parte. Yo le repito que esta seguridad suya le viene del efecto de distancia; de seguro, habríamos blasfemado contra Semmelweiss. Lo habríamos tenido por loco y su suerte no nos habría conmovido más allá de lo usual. De igual modo, y de acuerdo a nuestras actuales intenciones, habríamos defendido a Sócrates de la ira de los atenienses, a Cristo de sus crucificadores, a Bruno de la hoguera. Pero, esta generosidad sublime es efecto de la distancia y resulta difícil creer que tenga mayor asidero.

Por de pronto, convengamos que la manera como vemos hoy a Semmelweiss, Servet, Kammerer o Bruno, es función de nuestra propia época y no cabe pensar que así se les viera en la propia. Después de todo, lo que su propia época pensó de Bruno está abiertamente expresado en Brumo ardiendo y calcinándose en la hoguera. Veámonos entre la multitud, apretujados y ávidos de espectáculo. Representémonos, por un instante, viendo quemarse el cuerpo de Bruno, viendo como el resplandor de las llamas se dibuja en los rostros, viendo como se delinean en las bocas muecas entre horrorizadas y morbosas. Dígame, querido lector; ¿se abre paso usted entre la gente, enfrenta a los guardias, aparta a los inquisidores y libra Bruno? ¿Habría visto usted a Bruno como alguien sobradamente merecedor de tamaña decisión suicida? No. Toda esa fantasía suya es fruto de una composición de lugar absolutamente incongruente.

Concluyo pues, que nuestra indignación por la suerte de Semmelweiss resulta de una operación de sustitución hecha en el aire. Con toda seguridad, si usted y yo apareciéramos ahora en Budapest, año de 1865, y se nos acercara un señor con expresión de anormalidad en el rostro salivando con frecuencia en verdad chocante, diciéndonos:

“Me ayudan señores?, estoy repartiendo un panfleto contra los obstetras, los profesores del hospital, los estudiantes que practican disección de cadáveres, todos los cuales señores ignoran mis consejos sobre la fiebre puerperal, panfleto en el que los insulto, provoco y amenazo por sus crímenes...".

...Usted y yo nos miramos sorprendidos, perplejos, tratando de descifrar este extraño ser que nos ha salido al camino y nos obstaculiza la marcha, nos interrogamos mutuamente. Yo le hago a usted un gesto cómplice, usted me lo hace a mí, y ambos continuamos la caminata interrumpida, dejando atrás a ese raro caballero, algo loco a juzgar por sus ademanes. 